Jurnal Keperawatan Hang Tuah (Hang Tuah Nursing
Journal)
e-ISSN 0000-0000

\title{
PENERAPAN KOMUNIKASI TERAPEUTIK PERAWAT PADA SAAT TINDAKAN KEPERAWATAN
}

\author{
Rizki Lestari ${ }^{1}$, Siska Mayang Sari ${ }^{2}$, T. Abdur Rasyid ${ }^{3}$
}

Program Studi IImu Keperawatan STIKes Hang Tuah Pekanbaru

Korespondensi email:2 siskamyg@htp.ac.id

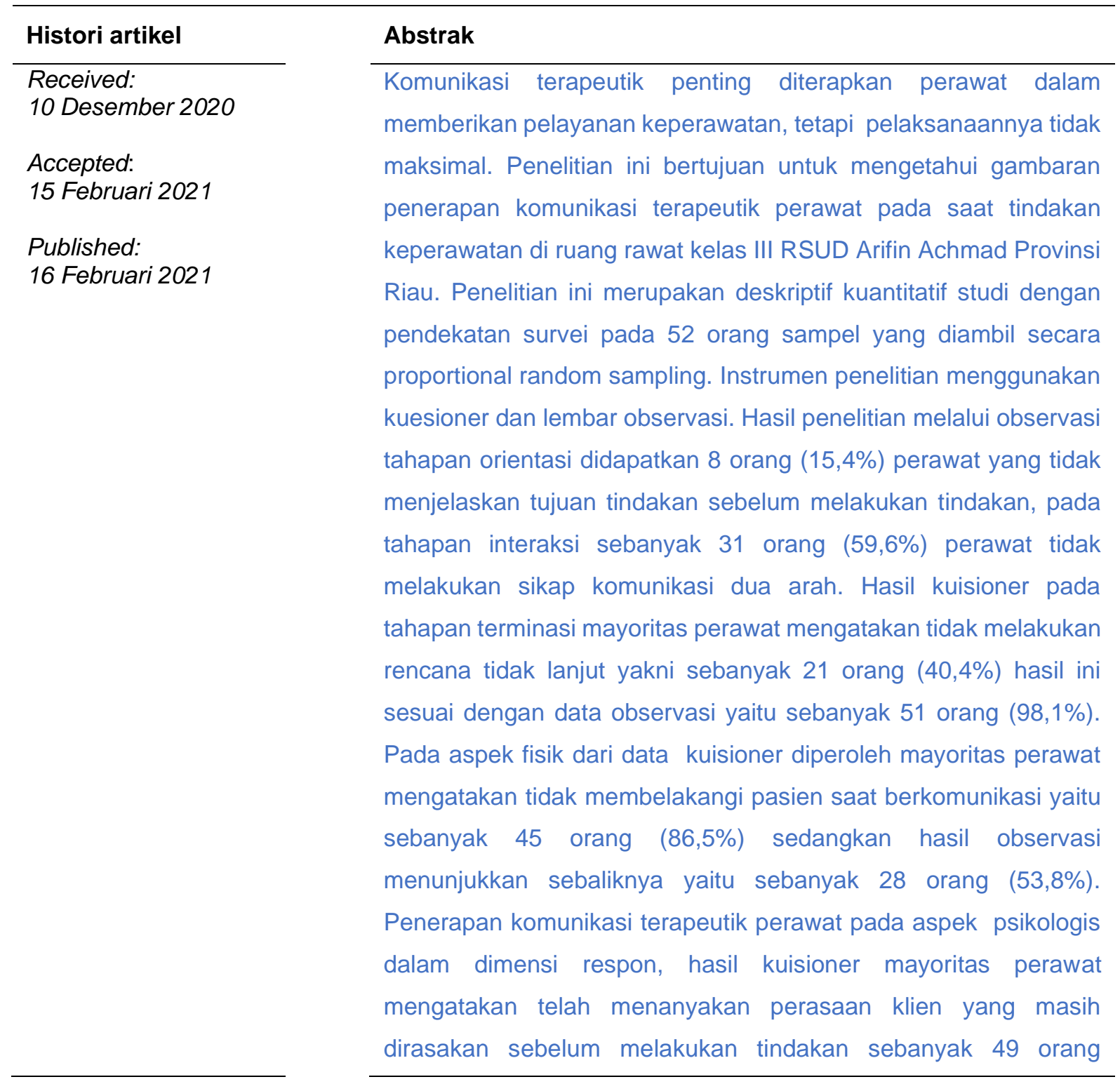


(94,3\%), sedangkan hasil observasi menunjukkan hasil sebaliknya yaitu sebanyak 26 orang (50\%), dan pada dimensi tindakan hasil kuisioner mayoritas perawat mengatakan segera melakukan tindakan sebanyak 51 orang $(98,1 \%)$, sementara hasil observasi menunjukkan hasil sebaliknya yakni sebanyak 36 orang $(96,2 \%)$. Disarankan kepada pihak rumah sakit untuk mengadakan supervisi serta pelatihan terkait penerapan komunikasi terapeutik perawat.

Kata kunci:komunikasi terapeutik, tindakan perawat, perawat

\begin{abstract}
Chronic disease is a condition of disease lasts for more than six months. If a person have chronic condition, the one of spiritual aspect to be affected. The purpose of this research to know the satisfaction of spiritual needs fulfillment with patient chronic disease on hospitalization. This was a quantitative study with descriptive and cross sectional design. The sample were 63 which taken by consecutive sampling. The data analyze were univariate, the result showed that 39,7 \% patient were in the late-age adult, 58,7\% patient were female, 47,6\% patient were unemployment, 49,2\% patient were high school graduates, 90,5\% patient were merried and $69,8 \%$ patient were breast cancer of diagnosed. The satisfaction of spiritual needs fulfillment were $69,8 \%$ not satisfied of patient, the majority of patient were not satisfied with maintain good relations and religious practices of fulfillment. The results of this study is expected to educational institutions and research sites to prepare healthy nurses spiritually in order to be able to carry out the fulfillment of spiritual needs optimally to patients and able to improve the quality of nursing services.
\end{abstract}

Keyword : Therapeutic communication , the nursing intervention, nurse

\title{
PENDAHULUAN
}

Pengetahuan masyarakat di era modern saat ini cendrung tinggi, sehingga masyarakat lebih kritis dalam memilih pelayanan dan memiliki kesadaran yang tinggi akan hak-hak yang harus diterimanya di pelayanan rumah sakit. Oleh karena itu rumah sakit harus mampu memahami kebutuhan, suka atau tidaknya konsumen pada pelayanan yang diberikan 
beserta alasannya. Sehingga rumah sakit harus terus melakukan perbaikan pada tingkat kualitas pelayanannya untuk memenuhi kepuasan konsumen.

Pada hasil penelitian yang dilakukan oleh Febriani \& Sugiono tahun 2012 tentang analisis kualitas pelayanan terhadap kepuasan konsumen, ia menyatakan bahwa dimensidimensi kualitas pelayanan yang mempengaruhi tingkat kepuasan adalah pengaruh daya tanggap (responsiveness) misalnya tanggap dalam menangani keluhan pasien, pengaruh empati (empathy) misalnya kepedulian terhadap kebutuhan pasien, serta ramah terhadap pasien dan keluarga, pengaruh jaminan (assurance) misalnya memberikan jaminan pelayanan kepada pasien, pengaruh kehandalan (reability) misalnya ketepatan waktu dalam memberikan pelayanan, dan pengaruh bukti fisik (tangible) misalnya penampilan sopan staff medis. Di dukung oleh penelitian Khotimah dkk tahun (2012) tentang hubungan komunikasi terapeutik perawat dengan kepuasan pelayanan keperawatan, ia mengartikan bahwa pelayanan dirumah sakit tidak hanya difokuskan pada angka kesembuhan pasien namun juga pada tingkat kepuasan terhadap pelayanan yang diterima pasien.

Perawat merupakan profesi yang memiliki intensitas paling tinggi dalam memberikan pelayanan rumah sakit, menjadikan tuntutan perawat untuk berkomunikasi dengan baik kepada pasien demi meningkatkan kepuasan pasien terhadap pelayanan keperawatan. Komunikasi dapat diartikan sebagai transfer informasi atau pesan dari pengirim pesan sebagai komunikator dan kepada penerima pesan sebagai komunikan. Terdapat enam komponen komunikasi agar dapat terjadi proses komunikasi yaitu komunikator, komunikan, pesan, media, kegiatan encoding, dan kegiatan decoding (Damaiyanti, 2010). Menurut Heri (2009), komunikasi dalam bidang kesehatan merupakan proses tukar informasi antara penerima dan pemberi pesan yang memiliki tujuan untuk menumbuhkan kepercayaan, menimbulkan kepuasan, meningkatkan pengobatan, dan menuju kesembuhan bagi pasien, yang disebut dengan komunikasi terapeutik.

Komunikasi terapeutik merupakan cara tenaga kesehatan menyampaikan pesan atau informasi kepada pasien dan keluarga terkait dengan kondisi kesehatan pasien, tindakan yang akan dilakukan kepada pasien baik pertama kali pasien datang kerumah sakit hingga pasien diperbolehkan untuk pulang. Komunikasi terapeutik adalah suatu hubungan interpersonal yang dilakukan perawat pada pasien, dimana perawat berupaya agar pasien mampu mengatasi baik masalahnya sendiri, maupun masalahnya dengan orang lain dan lingkungannya (Priyanto, 2009). Maka dari itu komunikasi terapeutik penting dilakukan oleh perawat.

Perawat sangat dituntut untuk mengaplikasikan komunikasi terapeutik kepada pasien maupun keluarga. Perawat merupakan profesi yang paling sering kontak langsung atau berkomunikasi 
dengan pasien. Menurut Nasir, dkk 2009, mengemukakan bahwa komunikasi terapeutik dilakukan dengan tujuan hubungan perawat dan pasien efektif dan dapat meningkatkan derajat kesehatan pasien. Dimana komunikasi terapeutik yang dilakukan tenaga keperawatan memiliki pengaruh terhadap motivasi kesembuhan bagi pasien dan meningkatkan kepuasan pasien terhadap pelayanan, terbukti dengan hasil penelitian yang dilakukan oleh Hardhiyani tahun (2013) tentang hubungan komunikasi terapeuti perawat dengan motivasi sembuh pada pasien rawat inap, ia mengatakan bahwa komunikasi terapeutik dengan motivasi sembuh pasien rawat inap saling mempengaruhi dimana semakin tinggi komunikasi terapeutik perawat semakin tinggi pula motivasi sembuh pasien rawat inap, serta penelitian Negi Sandhya, Harleen Kaur, Grace M Singh, Sanchita Pugazhendi tahun 2017, menyimpulkan bahwa komunikasi terapeutik yang dilakukan perawat dapat meningkatkan tingkat kepuasan pasien. Purwaningsih \& Karlina (2010), mengatakan seorang perawat dalam menerapkan komunikasi terapeutik kepada pasien harus hadir secara utuh baik secara fisik maupun psikologis, yang mana secara fisik meliputi, berhadapan, mempertahankan kontak mata, membungkuk kearah klien, mempertahankan sikap terbuka, dan tetap rileks. Secara psikologis meliputi dimensi respon dan dimensi tindakan.

Perawat dalam menerapkan komunikasi terapeutik pada pelaksanaan tindakan keperawatan penting memperhatikan aspek fisik dan psikologis tersebut, dikarenakan aspek tersebut merupakan komponen yang harus ada pada penerapan komunikasi terapeutik , jika tidak dilakukan maka komunikasi terapeutik belum dapat dikatakan dilakukan dengan optimal. Rumah Sakit Umum Daerah (RSUD) Arifin Achmad Provinsi Riau merupakan rumah sakit yang memiliki tugas dan fungsi mencakup upaya pelayanan perorangan, pusat rujukan, dan pembina Rumah Sakit Kabupaten/Kota se-Provinsi Riau. Perawat diharapkan perawat lebih tanggap dalam memberikan asuhan keperawatan pada pasien.

Dari hasil observasi pendahuluan peneliti pada tanggal 11 Maret 2017 di RSUD Arifin Achmad Provinsi Riau ruangan inap Dahlia kelas III dengan kriteria, perawat mengucapkan salam dan menyapa klien dengan menyebut nama klien sebelum tindakan keperawatan, memperkenalkan diri sebelum melakukan tindakan, perawat menanyakan tentang keluhan klien sebelum tindakan keperawatan, perawat menjelaskan tindakan atau prosedur yang akan dilakukan, perawat mempertahankan komunikasi selama tindakan, dan perawat menanyakan perasaan klien terhadap tindakan yang telah dilakukan, pada 5 orang perawat didapatkan hasil pelaksanaan komunikasi oleh perawat, 1 perawat yang hanya mengucapkan salam dan menanyakan keluhan sebelum melakukan tindakan, 3 perawat telah mengucapkan salam, memperkenalkan diri, menanyakan keluhan dan menjelaskan tindakan atau prosedur, 
sedangkan 1 perawat telah mengucapkan salam, menanyakan keluhan, menjelaskan tindakan, dan menanyakan perasaan klien terhadap tindakan.

Dari latar belakang ditas, maka peneliti tertarik untuk mengetahui dan melakukan penelitian dengan judul "Penerapan Komunikasi Terapeutik Perawat Pada Saat Pelaksanaan Tindakan Keperawatan".

\section{METODE PENELITIAN}

Jenis dan desain penelitian yang digunakan adalah penelitian deskriptif kuantitatif dengan pendekatan survey. Penelitian ini melihat gambaran penerapan komunikasi terapeutik (aspek fisik, dimensi respon, dan dimensi tindakan) dengan penerapan komunikasi terapeutik perawat.

Penelitian ini dilakukan di Rumah Sakit Umum Daerah (RSUD) Arifin Achmad Provinsi Riau, dikarenakan RSUD merupakan rumah sakit rujukan di Provinsi Riau, sehingga diharapkan memiliki pelayanan yang optimal khususnya dalam pelayanan keperawatan dengan menerapkan komunikasi terapeutik pada saat melakukan tindakan keperawatan. Pengambilan lokasi dikarenakan kemudahan dalam akses informasi, jarak, dan biaya. Kegiatan penelitian ini dimulai dari menyusun proposal sampai penyerahan laporan hasil penyusuan skripsi dari bulan November sampai Agustus 2017.

Populasi adalah keseluruhan jumlah yang terdiri atas obyek atau subyek yang mempunyai karakteristik dan kualitas tertentu yang ditetapkan oleh peneliti (sujerweni, 2014). Populasi pada peneliti ini adalah perawat pelaksana yang bekerja di 4 ruang rawat inap kelas 3 RSUD Arifin Achmad Provinsi Riau dengan jumlah perawat sebanyak 107 orang.

Menurut Sujarweni (2014) sampel adalah bagian dari sejumlah karakteristik yang dimiliki oleh populasi yang digunakan untuk penelitian. Dalam penelitian ini sampel yang terlibat adalah sebagian perawat pelaksana di ruang rawat inap kelas III RSUD Arifin Achmad Provinsi Riau.

Teknik sampling merupakan teknik pengambilan sampel (Sujarweni,2014). Pada penelitian ini, pengambilan sampel menggunakan Probability Sampling dengan teknik propotionate random sampling yaitu teknik yang digunakan bila populasi mempunyai anggota/unsur yang tidak homogen dan berstrata secara proporsional. Sugiyono (2014).

\section{HASIL DAN PEMBAHASAN}

Tabel 1. Distribusi Perawat Berdasarkan Usia Di Ruang Rawat Inap Kelas III RSUD Arifin Achamd Provinsi Riau ( $\mathrm{n}=52)$ 


\begin{tabular}{lllll}
\hline Mean & $\begin{array}{l}\text { Standar } \\
\text { Devisiasi }\end{array}$ & Min & Maks & Range \\
\hline 25,9 & 4,572 & 19 & 35 & 16 \\
\hline
\end{tabular}

Diperoleh bahwa usia perawat pelaksana minimal 19 tahun, maksimal 35 tahun dan rata rata usia perawat pelaksana yaitu 25 tahun.

Tabel 2. DistribusiPerawat Berdasarkan Jenis Kelamin, Pendidikan dan Lama Bekerja Di Ruang Rawat Inap Kelas III RSUD Arifin Achmad Provinsi Riau. $(\mathrm{n}=52)$

\begin{tabular}{lll}
\hline Variabel & $\mathrm{F}$ & $\%$ \\
\hline Jenis Kelamin & & \\
Laki-laki & 15 & 28,8 \\
Perempuan & 37 & 71,2 \\
\hline Pendidikan & & \\
DIII Kep & 28 & 53,8 \\
S1/Ners & 34 & 46,2 \\
\hline Lama Bekerja & & \\
$<5$ thn & 15 & 28,8 \\
$>10$ thn & 4 & 7,7 \\
5-10 thn & 33 & 63,5
\end{tabular}

Diperoleh bahwa jenis kelamin mayoritas perawat pelaksana yaitu perempuan sebanyak 37 orang $(71,2 \%)$. Berdasarkan pendidikan mayoritas tingkat pendidikan perawat pelaksana yaitu Diploma III Keperawatan yang berjumlah 28 orang (53,8\%) Sementara berdasarkan lama kerja mayoritas perawat pelaksana berada pada tingkat (5-10 tahun) yaitu sebanyak 33 orang $(63,5)$.

Tabel 3. Distribusi Frekuensi Jawaban Perawat tentang Pelaksanaan Tahapan Komunikasi Terapeutik Perawat $(n=52)$

\begin{tabular}{|c|c|c|}
\hline \multirow{2}{*}{$\begin{array}{l}\text { Tahap } \\
\text { Komunikasi }\end{array}$} & \multicolumn{2}{|c|}{ Hasil } \\
\hline & $\mathrm{F}$ & $\%$ \\
\hline \multicolumn{3}{|l|}{ Memperken } \\
\hline alkan diri & & \\
\hline
\end{tabular}




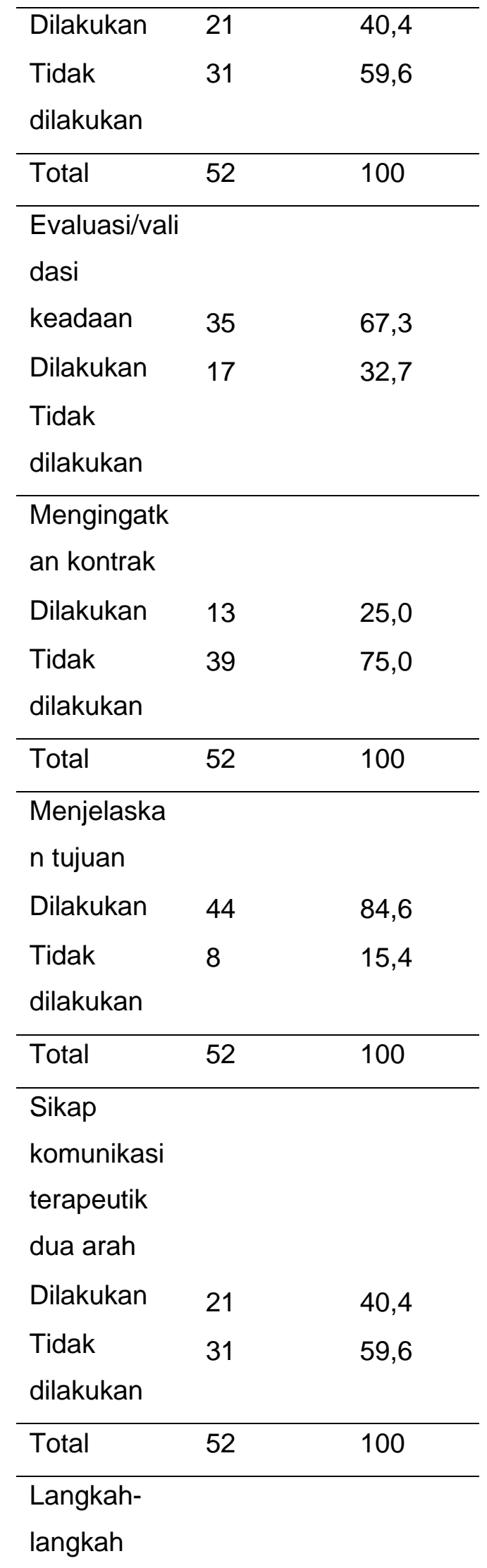




\begin{tabular}{lll}
\hline $\begin{array}{l}\text { sesuai } \\
\text { rencana }\end{array}$ & 35 & 67,3 \\
$\begin{array}{l}\text { Dilakukan } \\
\text { Tidak }\end{array}$ & 17 & 32,7 \\
dilakukan & & \\
\hline Total & 52 & 100 \\
\hline Rencana & & \\
tindak lanjut & & \\
$\begin{array}{l}\text { Dilakukan } \\
\text { Tidak }\end{array}$ & 1 & 1,9 \\
dilakukan & 51 & 98,1 \\
\hline Total & 52 & 100 \\
\hline Kontrak & & \\
yang akan & & \\
datang & 23 & 44,2 \\
Dilakukan & 29 & 55,8 \\
Tidak & & \\
dilakukan & & \\
\hline Total & 52 & \\
\hline
\end{tabular}

Orientasi

Berdasarkan hasil penelitian terdapat perbedaan dari hasil kuesioner dengan hasil observasi, pada tahap orientasi diperoleh bahwa $100 \%$ perawat memperkenalkan diri, tetapi pada saat dilakukan observasi sebanyak 31 orang (59,6\%) perawat tidak memperkenalkan diri sebelum tindakan. sama dengannya pada mengingatkan kontrak dalam hasil kuesioner didapatkan 10 (19,2\%) tidak melakukan dan pada saat dilakukan observasi sebanyak 39 (75,0\%) perawat tidak melakukan.

Hal ini sangat disayangkan dikarenakan tahap orientasi merupakan sesuatu yang sangat penting dikarenakan pada tahap ini perawat dapat membina hubungan saling percaya, sesuai dengan teori yang dinyatakan oleh Direja (2008), yaitu dalam membina hubungan perawat dan klien yang kunci utama adalah terbinanya saling percaya, adanya komunikasi yang terbuka. Teori tersebut didukung oleh teori yang dikemukakan oleh A.Patricia Akbar, Indahwaty Sidin, dan Syahrir A. Pasinring (2013), mengatakan bahwa sangat penting bagi perawat melaksanakan tahapan ini dengan baik karena tahapan ini merupakan dasar bagi hubungan 
interpersonal antara perawat dan pasien, sehingga pasien belajar bagaimana menerima dan diterima orang lain.

Berdasarkan dari hasil penelitian dan ditunjang oleh teori diatas, peneliti berpendapat bahwa tahapan orientasi dalam komunikasi terapeutik belum dilakukan secara maksimal, seharusnya sebagai perawat pelaksana yang melakukan tindakan harus melakukan tahapan orientasi terlebih dahulu untuk dapat menciptakan hubungan yang saling percaya antara klien dan perawat serta komunikasi yang terbuka.

Interaksi

Pada hasil penelitian terdapat perbedaan dari hasil kuesioner dengan hasil observasi yang telah dilakukan. Pada tahap interaksi hasil kuesioner yang didapatkan sebanyak 4 (7,7\%) perawat yang tidak melakukan sikap terapeutik yang baik pada saat interaksi, dan sebanyak $3(5,8 \%)$ perawat tidak melakukan langkah-langkah tindakan sesuai rencana, sedangkan pada hasil observasi yang dilakukan didapatkan 31 (59,6\%) perawat tidak menerapkan sikap terapeutik yang baik pada saat interaksi, dan sebanyak 17 (32,7\%) perawat yang tidak menerapkan langkah-langkah tindakan sesuai rencaa.

Hal ini sangat disayangkan, dikarenakan pada tahap interaksi ini yang paling memungkinkan kerja sama antara perawat-klien terjalin. Seperti teori yang telah dikemukakan oleh Direja (2008), yaitu tahap interaksi ini merupakan dimana kerjasama terapeutik perawatklien palin banyak dilakukan, dengan cara melaksanakan kegiatan sesuai dengan perencanaan, sehingga perawat dapat menggali stressor dan dapat mendukung perkembangan kesehatan klien. Menurut A.Patricia Akbar, Indahwaty Sidin, dan Syahrir A. Pasinring (2013) dalam tahap ini perawat mendengarkan secara aktif dan dengan penuh perhatian sehingga mampu membantu asien untuk mendefenisikan masalah yang sedang dihadapi oleh pasien dan mencari penyelesaian masalah pasien.

Berdasarkan hasil penelitian diatas dan ditunjang dari teori diatas peneliti berpendapat bahwa perawat harus melakukan tahap interaksi ini, dikarenakan tahap interaksi sangat penting dan di memungkinkan perawat dapat menggali informasi klien sehingga dapat mendukung perkembangan kesehatan serta perubahan prilaku yang adaptif . Terminasi

Pada hasil penelitian juga terdapat perbedaan pada hasil kuesioner dan hasil observasi yang telah dilakukan. Pada tahap terminasi hasil kuesioner didapatkan sebanyak 21 (40,4\%) perawat yang tidak melakukan rencana tindak lanjut dan tidak melakukan kontrak yang akan datang, dan pada hasil observasi yang dilakukan didapatkan sebanyak 51 (98,1\%) perawat yang tidak melakukan rencana tindak lanjut, dan 29 (55,8\%) perawat yang tidak melakukan kontrak yang akan datang. 
Hal ini sangat disayangkan dikarenakan terminasi merupakan tahapan akhir dalam suatu tindakan yang mana perawat dapat mengevaluasi perkembangan kesehatan klien. Sesuai dengan teori yang telah dikemukakan oleh Direja (2008) bahwa terminasi adalah satu dari tahapan yang sulit tapi penting dari hubungan terapeutik perawat-klien. Tahap ini saat dapat mengevaluasi respon pasien akan suatu tindakan, merencanakan tindak lanjut yang akan dilakukan. Kusumawati, Farida dan Hartono, Yudi, mengemukakan bahwa pada fase terminasi perawat dank lien mengekspresikan perasaan serta mengevaluasi perkembangan yang dicapai klien, yang kemudian disesuaikan dengan pencapaian tujuan pada rencana keperawatan. Riyadi, Sujono, dan Purwanto Teguh (2009), mengemukakan bahwa pada tahap interaksi perawat dapat menghilangkan dan mengurangi tingkat kecemasan cemas klien, meningkatkan kemandirian dan tanggung jawab terhadap diri sendiri dan mengembangkan mekanisme koping yang kontruktif. Perubahan perilaku yang adaptif merupakan tanda bahwa tujuan telah tercapai.

Berdasarkan hasil penelitian dan teori diatas peneliti berpendapat bahwa belum seluruh perawat yang melakukan tahap terminasi dengan baik, sehingga tujuan komunikasi terapeutik pun tidak tercapai dengan baik. Seharusnya tahap terminasi harus dilakukan oleh perawat dikarenakan pada tahap terminasi perawat dapat mengetahui perkembangan kesehatan pasien.

Tabel 4. Distribusi Frekuensi Hasil Observasi tentang Aspek-aspek Komunikasi Terapeutik $(n=52)$

\begin{tabular}{llc}
\hline Aspek & \multicolumn{2}{l}{ Hasil } \\
\cline { 2 - 3 } & $\mathrm{F}$ & $\%$ \\
\hline $\begin{array}{l}\text { Berhadapan saat } \\
\text { berkomunikasi } \\
\text { Dilakukan }\end{array}$ & 24 & 46,2 \\
Tidak dilakukan & 28 & 53,8 \\
\hline Total & 52 & 100 \\
\hline Mempertahankan & & \\
kontak mata & & \\
Dilakukan & 31 & 59,6 \\
Tidak dilakukan & 21 & 40,4 \\
\hline Total & 52 & 100 \\
\hline
\end{tabular}




\begin{tabular}{|c|c|c|}
\hline \multicolumn{3}{|l|}{ Membungkuk } \\
\hline \multicolumn{3}{|l|}{ kearah klien ketika } \\
\hline \multicolumn{3}{|l|}{ mendengarkan } \\
\hline klien & 10 & 19,2 \\
\hline Dilakukan & 42 & 80,8 \\
\hline \multicolumn{3}{|l|}{ Tidak dilakukan } \\
\hline Total & 52 & 100 \\
\hline \multirow{3}{*}{\multicolumn{3}{|c|}{$\begin{array}{lr}\text { Relaks } & \text { atau } \\
\text { tenang } & \text { ketika } \\
\text { berbicara } & \text { kepada }\end{array}$}} \\
\hline & & \\
\hline & & \\
\hline & 52 & 100 \\
\hline Dilakukan & 0 & 0 \\
\hline \multicolumn{3}{|l|}{ Tidak dilakukan } \\
\hline total & 52 & 100 \\
\hline \multicolumn{3}{|l|}{$\begin{array}{l}\text { Meminta maaf } \\
\text { atas }\end{array}$} \\
\hline ketidaknyamanan & 8 & 15,4 \\
\hline Dilakukan & 44 & 84,6 \\
\hline \multicolumn{3}{|l|}{ Tidak dilakukan } \\
\hline Total & 52 & 100 \\
\hline \multicolumn{3}{|l|}{ Menanyakan } \\
\hline $\begin{array}{ll}\text { perasaan } & \text { klien } \\
\text { yang } & \text { masih }\end{array}$ & & \\
\hline dirasakan & 26 & 50 \\
\hline Dilakukan & 26 & 50 \\
\hline \multicolumn{3}{|l|}{ Tidak dilakukan } \\
\hline Total & 52 & 100 \\
\hline \multicolumn{3}{|l|}{ Tidak } \\
\hline \multicolumn{3}{|l|}{ menjelaskan } \\
\hline informasi secara & & \\
\hline akurat & 25 & 48,1 \\
\hline Dilakukan & 27 & 51,9 \\
\hline
\end{tabular}




\begin{tabular}{|c|c|c|}
\hline \multicolumn{3}{|l|}{ Tidak dilakukan } \\
\hline Total & 52 & 100 \\
\hline Tidak & & \\
\hline menjelaskan efek & & \\
\hline samping & & \\
\hline pengobatan & 13 & 25 \\
\hline Dilakukan & 39 & 75 \\
\hline Tidak dilakukan & & \\
\hline Total & 52 & 100 \\
\hline $\begin{array}{l}\text { Perawat segera } \\
\text { melakukan }\end{array}$ & & \\
\hline tindakan & 16 & 30,8 \\
\hline Dilakukan & 36 & 69,2 \\
\hline Tidak dilakukan & & \\
\hline Total & 52 & 100 \\
\hline $\begin{array}{l}\text { Perawat memberi } \\
\text { tahu efek samping } \\
\text { pengobatan }\end{array}$ & & \\
\hline Dilakukan & 39 & 75 \\
\hline Tidak dilakukan & 13 & 25 \\
\hline Total & 52 & 100 \\
\hline
\end{tabular}

Pada hasil penelitian didapatkan perawat yang tidak melakukan berhadapan atau membelakangi pasien ketika melakukan komunikasi sebanak 28 perawat dari 52 perawat $(53,8 \%)$, dan perawat yang tidak membungkuk kearah klien ketika mendengarkan klien berbicara sebanyak 42 perawat dari 52 perawat $(80,8 \%)$.

Hal ini menggambarkan bahwa pelaksanaan komunikasi terapeutik pada aspek fisik belum dilakukan secara maksimal. Dikarenakan menurut Damaiyanti (2010), dalam komunikasi terapeutik harus terdapat sikap atau cara untuk menghadirkan diri secara fisik yang dapat memfasilitasi komunikasi terapetuik. Dalam aspek fisik berhadapan sangat penting dilakukan dikarenakan menurut Riyadi, Sujono dan Purwanto Teguh (2009) sikap berhadapan menunjukkan kesiapan perawat dalam melayani dan mendengarkan keluhan klien, serta sikap 
membungkuk kearah klien juga sangat penting karena menunjukkan keinginan untuk menyatakan atau mendengarkan semua apa yang dikatakan klien.

Berdasarkan hasil penelitian dan teori diatas peneliti berpendapat bahwa pelaksanaan komunikasi terapeutik pada aspek fisik sangat penting diterapkan, sedangkan perawat masih belum menerapkannya dengan cukup baik. Seharusnya seluruh perawat menerapkan aspek tersebut agar perawat mampu menhadirkan diri secara fisik.

\section{DAFTAR PUSTAKA}

Damaiyanti, M. (2010). Komunikasi terapeutik dalam paktik keperawatan. Bandung: Refika Aditama

Debora, O. (2011). Proses keperawatan dan pemeriksaan fisik. Jakarta: SalembaMedika.

Direja, A.H.S. (2011). Asuhan keperawatan jiwa. Yogyakarta: Nuha Medika.

Doenges. M. E. (2009). Rencana asuhan keperawatan psikiatri. (Edisi 3). Jakarta: EGC.

Febriani, V. A. \& Sugiono. (2012). Analisis kualitas pelayanan terhadap kepuasan konsumen. Diponegoro journal of management, 1(1), dari http://ejournalsl.undip.ac.id/index.php/dbr

Hardhiyani, R. (2013). Hubungan komunikasi terapeutik perawat dengan motivasi sembuh pada pasien rawat inap. Development and Clinical Psychology. 2(2), dari http://journal.unnes.ac.id/sju/index.php/dcp.

Heri D.J.M. (2009). Promosi kesehatan. Jakarta : EGC.

Hidayat, A.A.A. (2008a). Pengantar konsep dasar keperawatan. Jakarta: Salemba Medika. . (2008b). Metode Penelitian keperawatan dan teknik analisis. Jakarta: Salemba Medika.

Khotimah, Nurul. M. \& Ning. I. (2012). Hubungan komunikasi terapeutik perawat dengan kepuasan pelayanan keperawatan di ruang Inayah Rumah Sakit PKU Muhammadiyah Gombong. Jurnal ilmiah kesehatan keperawatan. 8(2). Dari http://ejournal.stikesmuhgombong.ac.id/index.php/JIKK/article/view/70

Nasir A,. Abdul M,. Muhammad S,. Wahit I.M,. (2009). Komunikasi dalam keperawatan: Teori dan Aplikasi. Jakarta: Salemba Medika.

Negi, S., Harleen, K., Garce, M. S., \& Sanchita, P. (2017). Quality of nurse patient therapeutic communication stay. International jurnal of Medical Science and Public Health. Dari http://creativecommons.org/licenses.org/licenses/by/4.0/

Nursalam. (2008).Konsep dan penerepan metodeologi penelitian ilmu keperawatan: Pedoman skripsi, tesis, dan instrument penelitian keperawatan. Jakarta: Salemba Medika. 
Purwaningsih, W. \& Ina. K. (2010). Asuhan keperawatan jiwa. Yogyakarta: Nuha Medika.

Priyanto, A. (2009). Komunkasi dan konseling : Aplikasi dalam sarana pelayanan kesehatan untuk perawat dan bidan. Jakarta: Salemba Medika.

Rohmah N \&Walid Saiful. (2012). Proses keperawatan teori \& aplikasi. Jogjakarta: AR-Ruz Media.

Rifani, Nisya \& Hartanti Sulihandari. (2013). Prinsip-prinsip dasar keperawatan. Jakarta: Dunia Cerdas.

Rumah Sakit Umum Daerah Arifin Achmad. (2016). Pengambilan data survey awal tahun 2017.

STIKes Hang Tuah Pekanbaru. (2016). Panduan skripsi program studi ilmu keperawatan. Pekanbaru: STIKes Hang Tuah Pekanbaru.

Sugiyono. (2014). Metode penelitian kuantitatif, kualitatif, dam R\&D. Bandung: Alfabeta.

Sujarweni, V. W. (2014). Metodologi penelitian keperawatan. Yogyakarta: Penerbit Gava Media.

Taufik M \& Julane. (2010). Komunikasi terapeutik dan konseling dalam praktik keperawatan. Salemba. Jakarta: Medika. 